Estudios Románicos, Volumen 30, 2021, pp. 231-241

ISSN: 0210-4911

eISSN: $1989-614 \mathrm{X}$

DOI: https://doi.org/10.6018/ER.466941

\title{
EL VIAJE NARRATIVO Y EL LIBRO DE VIAJE MEDIEVALES
}

(The narrative journey and the travel book in the Middle Ages)

\author{
Fernando Carmona Fernández \\ Universidad de Murcia
}

A Eugenia Popeanga, por su jubilación y en reconocimiento de sus estudios sobre libros de viaje

\begin{abstract}
This article points out the importance of travel books in the medieval literary story that responds to the sociocultural awakening of the 12th century and characterizes the realist novel of the 13th and 14th centuries. Particularly noteworthy are Jehan Renart's Escoufle, Philippe de Beaumanoir's Manekine and Jean Maillart's Roman du comte d'Anjou. These novels are contemporary to the expansion of travel books and are connected to the concept of travel.
\end{abstract}

Keywords: narrative travel; medieval travel books; Escoufle by Jehan Renart; Manekine by Philippe de Remy; Roman du comte d'Anjou by Jean Maillart; Mirabilia descripta by Jordán de Séverac.

Resumen: El artículo señala la importancia del viaje en el relato literario medieval que responde al despertar sociocultural del siglo xir y caracteriza la llamada novela realista de los siglos XIII y XIV. En particular, al Escoufle de Jehan Renart, a la Manekine de Philippe de Remy y al Roman du comte d'Anjou de Jean Maillart. Novelas coetáneas a la expansión de los libros de viaje y ligadas a estos en la concepción del viaje.

Palabras clave: viaje narrativo; libros de viajes medievales; Escoufle de Jehan Renart; Manekine de Philippe de Remy; Roman du comte d'Anjou de Jean Maillart; Mirabilia descripta de Jordán de Séverac.

\footnotetext{
*Dirección de correspondencia: fcarmona@um.es
} 
Pretendo, en este artículo, considerar la interrelación entre el viaje de la ficción narrativa y el de los libros de viaje ${ }^{1}$. Ambas modalidades literarias se desarrollan y convergen en el siglo XIII respondiendo a la transformación sociocultural y a la literaria heredada del siglo anterior.

Se podría hablar de la transversalidad de la idea de viaje en cuanto que no deja de concebirse la existencia y la actividad humana como viaje. Así, la vida era un camino a recorrer (homo viator) y la cultura del occidente medieval estaba ligada al movimiento. La transformación económica de la llamada segunda edad feudal se debe, para Marc Bloch, al "intenso movimiento de la población que, de 1050 a 1250 aproximadamente, transformó la faz de Europa en los confines del mundo occidental" (cit. por Le Goff 1972: 6). Roturaciones y cambios en los sistemas de cultivo facilitan el incremento de población y la aparición de las ciudades. Los caminos se llenan de peregrinos, de mercaderes, de caballeros, de cruzados, juglares, estudiantes. "En casi todas las clases sociales, el vagabundeo, errar, se convierte en una necesidad, una costumbre, una idea" (Le Goff 1972: 49). No se concibe actividad humana que no esté ligada a un itinerario o viaje (para santo Tomás, Dios es el primer motor de lo existente); ni el estudio sin el desplazamiento físico; es decir, requiere hacerlo "in terra aliena". Es más, el estudio mismo es un viaje ${ }^{3}$; el acceso al templo, espacio sagrado por antonomasia, es un recorrido por el universo y la historia humana ${ }^{4}$.

No es extraño que la literatura surja en un itinerario, en los caminos de peregrinación. J. Bédier, en una conocida frase, resume el origen de los cantares de gesta ("au commencement était la route, jalonnée de sanctuaires”, 1908: 135); señaló la route, el camino, como el lugar del comienzo del cantar de gesta. La literatura europea nace ligada a la ruta del peregrino como ocurre en el Liber sancti Jacobi: es significativo que reproduzca este manuscrito una guía del peregrino de París a Santiago junto a un cantar de gesta (Crónica del Pseudo Turpín). Uno de los primeros cantares de gesta, Pèlerinage de Charlemagne, es también una especie de descubrimiento viajero de Bizancio.

$1 \quad$ El corpus narrativo de los siglos XIII y XIV del que partimos coincide en gran medida con el utilizado en nuestro trabajo "El espacio narrativo a la aparición de la literatura de viajes del siglo XIII", en Maravillas, peregrinaciones y utopías: literatura de viajes en el mundo románico (2002). Este artículo completa el anterior trabajo en cuanto que el primero, como el título indica, realiza una tipología evolutiva de la concepción del espacio literario. En el presente trabajo, nos centramos en el realismo narrativo en consonancia con la concepción del relato del viaje; es decir, como indica el título, entre el viaje novelesco y el vivido "contado".

2 Es una de las exigencias fundamentales para el estudioso que pone Bernardo de Chartres (Carmona 2001: 76).

3 El saber se concibe como viaje por el universo que va del conocimiento de lo inmediato y terrenal a la contemplación divina. En el segundo tratado de El convivio, Dante (1949: 43-74) establece una correspondencia entre las siete artes y los siete cielos, haciendo un recorrido por el universo: Luna (Gramática), Mercurio (Dialéctica), Venus (Retórica), Sol (Aritmética), Marte (Música), Júpiter (Geometría), Saturno (Astrología). Añade el Cielo Estrellado (Física y Metafísica) y el Cielo Cristalino o Primum Mobile (Ética). Por encima, finalmente, el Empíreo (Teología).

$4 \quad$ El templo expresaba el cronotopo medieval en su totalidad. Atrio, nave y transepto simbolizaban las tres etapas de la vida cristiana: purificación, iluminación y unión con Dios que correspondían con bautismo, enseñanza sagrada y eucaristía. La disposición del atrio, al este del edificio, señalaba la ubicación bíblica del Paraíso terrenal; el ábside colocado al otro extremo, con la representación del Juez Supremo, indicaba el fin de los tiempos. El fiel cristiano, en su desplazamiento por el templo, recorre el espacio de su existencia y el de la historia de la cristiandad (cf. Burkhardt 1999: 11-14). 


\section{Cambios de itinerario: del desfiladero al castillo.}

Atendiendo a la percepción del espacio de los siglos XII y XIII, encontramos la falta de descripción de la naturaleza en los comienzos de la narrativa. En el Cantar de Roldán, se reduce, a veces, a la breve pincelada de un verso: "altos son los montes y los valles tenebrosos" (v. 814). A modo de eco el verso se irá repitiendo en el cantar ${ }^{5}$. Con la repetición, se enriquece connotativamente en cada momento dramático de su ubicación; los calificativos que los enmarcan -altos/tenebrosos- si bien aluden al desfiladero de Roncesvalles, remiten también a la verticalidad de lo alto y lo bajo, -cielo/infierno-. El adjetivo tenebroso es premonitorio del destino del héroe -oscuridad de la muerte- y del ataque de los sarracenos que serán presentados como seres demoníacos procedentes del mundo de las tinieblas; además, el término anticipa el dolor de los caballeros y del emperador del que participa el público que escucha el cantar. El verso se repite abriéndose, pues, en una pluralidad de significaciones relegando la materialidad de lo designado ${ }^{6}$.

Podríamos hablar de un espacio enajenado, vertical y transcendido, como he señalado en otra ocasión (Carmona 2002: 327-329), que da sentido al cantar como exaltación de la muerte del héroe, ofreciendo su guante al cielo de donde bajan los ángeles para subir su alma; o al que se dirige Carlomagno para detener el sol. El Cantar responde a una concepción neoplatónica y simbólica que trata las cosas como signos cuyas significaciones a desentrañar son la verdadera realidad. Así, a principios del XII, Hugo de San Víctor fundamenta el conocimiento en la alegoría. Sobre este siglo, escribe E. Gilson: "Muchos cantan la naturaleza, pero ninguno piensa en observarla. [...] Para un pensador de este tiempo, conocer y explicar una cosa consiste siempre en mostrar que esa cosa no es lo que parece ser; que es el símbolo o el signo de una realidad más profunda; que anuncia o significa otra cosa" (1976: 320, subrayados del autor).

Al pasar a la segunda mitad del XII, con la narración artúrica y bretona, el espacio cerrado (desfiladero de Roncesvalles) y vertical (comunicación con lo sobrenatural) se transforma en abierto y horizontal. Se trata de la narración de un itinerario de ida y vuelta. El caballero parte de Camelot y regresa tras un viaje transformador. En el viaje ha tenido lugar una sucesión de pruebas; es decir, la aventura a la que el caballero debe su nombre y su identidad como tal. La aventura finaliza con una prueba excepcional y culminante, el encuentro con lo extraordinario, y hasta con el Otro Mundo.

El relato "proyecta así como narración lo que es descubrimiento y (por así decirlo) colonización de un espacio de límites inexplorados [...]. La aventura pone en marcha un dinamismo que orienta la búsqueda, como un itinerario orienta el viaje" (Zumthor 1993: 369).

En el itinerario artúrico destacan tres lugares: el castillo, el bosque y el vergel. El castillo y su entorno es el espacio caballeresco por excelencia. Se presenta como realidad y ficción a la vez. El castillo se alza en la altura encaramado en un monte, en una colina o un acantilado; dominando el bosque o la llanura. Es un espacio abierto para el caballero. Sale de uno

$5 \quad$ El verso se repite posteriormente: "Altos son los montes tenebrosos y grandes" (v. 1830); "altos son los montes y muy altos los árboles" (v. 2271); "y pasan los montes y rocas muy altas" (v. 3125).

6 J. Paredes ha considerado estos versos con relación al Poema del Cid (2012: 78-80). 
para entrar en otro. Los demás espacios, habitados o no, como bosques, ríos, villas son lugares de paso. El castillo es el lugar de prueba y aventura. En el de la Pésima aventura, Ivain tendrá que luchar con dos demonios para liberar a cien doncellas esclavizadas y explotadas laboralmente o Perceval no romperá el encantamiento del Castillo del Grial. ${ }^{7}$

Si el castillo es un lugar en el que el caballero puede encontrar inesperados enemigos, el bosque representa el universo salvaje frente a la civilidad del castillo. Lugar de retiro y penitencia para ermitaños, de pastoreo por parte de monstruosos villanos, de refugio para proscritos que están fuera de la ley o enloquecidos enamorados; lugar también de peligros inesperados o de hadas y fuentes que nos sitúan en un mundo mágico, pero, a su vez, espacio de degradación y de reducción a la animalidad.

La armonización de lo civilizado y de lo salvaje tiene lugar en el vergel, ubicado junto o cercano al castillo. Jardín idílico donde los caballeros cortejan a las damas y en el que tiene lugar la conquista amorosa cortés. Eco del paraíso terrenal y derivado del locus amoenus se convierte en espacio de "delit", de deleite, hortus conclusus, espacio que se cierra para el placer y el amor (Zumthor 1993: 51-107 y 1994: 104-7; Dubost 1991: 243-425). Pero, a la vez, es un lugar peligroso porque allí puede ser víctima de un enemigo infernal (Carmona 2016: 207-220).

\section{El itinerario no caballeresco: el burgo como destino. El milano de Jean Renart. La Manekine de Philippe de Remy. Roman du comte d'Anjou de Jean Maillart}

Tras la literatura caballeresca artúrica de la segunda mitad del XII, a principios del siguiente siglo, se desarrolla una corriente narrativa en verso denominada realista o gótica con la producción de Jean Renart, unas décadas después con la de Philippe de Remy y prolongada hasta principios del XIV con Jean Maillart, por señalar los más representativos. Sus narraciones conllevan un nuevo espacio e itinerario de los personajes.

Los lugares y seres fantásticos son sustituidos por otros reales y cercanos. Del caballero errante en busca de aventuras extraordinarias, pasamos a enamorados separados contra su voluntad y entregados a la búsqueda mutua. El itinerario de la aventura caballeresca se transforma en búsqueda viajera. La reducción al espacio y al tiempo contemporáneos y la eliminación de lo maravilloso artúrico ha llevado a calificar la producción de estos autores como "realista". Los espacios fantásticos se sustituyen por los geográficamente conocidos. El castillo imaginario por el burgo del viajero contemporáneo. Sobre lo maravilloso y simbólico se impone lo cotidiano.

En El milano (1202) de Jean Renart, la joven Aelis buscando a su enamorado se aloja en Toul, acompañada de Isabel, una joven que la había acogido en su pobre casa, y prosigue su búsqueda camino de Normandía. Pasan por Châlons, Rouen, Montivi-

$7 \quad$ Se puede seguir con una larga lista de ejemplos: Boores será seducido mágicamente por una doncella en el Castillo de la Marca. Perlevaus vencerá a un diablo en el Castillo de la Torre de Cobre. Lanzarote pasará pruebas en el de La Dolorosa Guardia, en el de las Damas, en el de los Grifos, en el Inexpugnable, etc. Sobre estos y otros castillos, cf. Alvar: 1991: 80-8; las páginas de Dubost bajo el epígrafe "Le château de l'aventure romanesque", 1991: 366-389; Duce García establece una tipología de castillos encantados referida a la literatura española (2005: 213-231).

8 Lejeune-Dehousse 1978: 400-453. También se han designado como "romans de estilo gótico" (Louison 2004). 
1liers. Tras más de dos años de infructuosa búsqueda y agotados los recursos, se asientan en Montpellier trabajando como bordadoras.

$\mathrm{Su}$ enamorado, Guillermo, no hace un itinerario menor; llega a Santiago a una hospedería importante de peregrinos, cuyo dueño lo contrata como su principal administrador. Por un peregrino, podrá orientar de nuevo su búsqueda volviendo a Montpellier donde tendrá lugar el fortuito y feliz reencuentro de los enamorados.

La comparación de dos relatos inspirados en el mismo argumento, Manekine de Philippe de Remy y el Roman du comte d'Anjou de Jean Maillart, permite observar el cambio narrativo del viaje entre la mitad del xIII y principios del siglo siguiente.

En La Manekine (1230-1240), el rey de Hungría ha concedido en el lecho de muerte de su esposa el don en blanco de casarse con aquella que se le parezca más. Por lo que se ve obligado a casarse con su hija ya que es la única del reino con tal parecido. Para evitar el incesto, ella se amputa la mano y huye de la condena a muerte, ordenada por su padre, en una embarcación sin vela ni remo. En un rápido viaje, aparece en Escocia, cuyo rey se enamora y se casa con ella; pero, víctima de otra intriga y obligada a otra huida con su hijo y también en un barco sin vela, llega a Roma donde es acogida por un rico senador. Mientras tanto, el rey de Escocia regresa de los torneos, descubre lo ocurrido a su esposa e inicia un largo viaje en su busca que le lleva de la India Mayor al septentrión. Finalmente, se dirige a Roma, a la vez que el arrepentido padre de la Manekine, el rey de Hungría. Ante el Papa, se efectuará el encuentro de todos y el final feliz, sin faltar la recuperación milagrosa de la mano amputada. El relato se cerrará con otra sucesión de viajes marinos de los jóvenes monarcas a Armenia, Hungría y, después, a Escocia. Itinerarios cortos y detallados, bien conocidos por el autor', se alternan con otros viajes que recorren todo el mundo conocido en la época. El del rey de Escocia no es menor que el de su esposa, ya que recorre todo puerto e isla conocidos y países sólo poblados por fieras salvajes, serpientes y escorpiones, desde la India oriental al septentrión.

El dilatado espacio geográfico y social de La Manekine, al pasar a la narración de Jean Maillart, el Roman du comte d'Anjou (1316), se reduce al itinerario real y físico que pueden recorrer los personajes. Las plegarias a la Virgen no facilitan, en este relato, la embarcación sin vela ni remo que transportaba al otro extremo de Europa a la protagonista del relato anterior ${ }^{10}$. La hija del conde de Anjou y la nodriza que la acompaña sufren las penalidades de la huida por un bosque hostil, la frugalidad de la comida propia de pobres campesinos (un mendrugo mohoso) y un alojamiento no mejor. Llegan a Orleans, donde son acogidas por una viuda y su hija, unas pobres

9 A un calendario preciso de los acontecimientos, se une la precisión geográfica del itinerario de sus personajes: nuestra protagonista llega al puerto de Berwick, la corte se reúne en Dundee; la reina madre, contrariada por el matrimonio, se retira a Perth. En el puerto de esta ciudad, tiene lugar la despedida de los esposos y el embarque del rey para los torneos en Francia. Tras una noche de navegación llega a Dam, donde el rey de Escocia se informa de que el conde de Flandes está en Gante preparando el torneo y se dirige a esta ciudad. Recorre Ressons, Lille y Épernay. La reina, a su vez, embarcado el rey hacia Francia, regresa a Berwick y, de aquí, a Dundee. De la misma manera, el itinerario del mensajero que lleva la noticia al rey del nacimiento de su hijo es presentado detalladamente (cf. Carmona 2002: 331-333).

10 Maillart elimina lo maravilloso céltico, como la travesía marítima sin vela ni remos de la tradición legendaria celta (Tristán, Guigemar); y también lo maravilloso cristiano; al suprimir que la joven se corte la mano, hace innecesario el milagro de su recuperación. 
obreras cuya indigencia no les permite comer y dormir mejor que en el alojamiento anterior ${ }^{11}$. Ejercen, como en el relato de Jean Renart, de bordadoras; pero, acosada nuestra protagonista por unos jóvenes burgueses, se encaminan a Lorris. En la espesura de un bosque se encuentran con el castellano de Lorris, que las alberga en su castillo donde la conoce el conde de Bourges y con el que contrae matrimonio. De nuevo, es víctima de una conspiración, ahora por parte de la tía del conde; y tiene lugar otra penosa huida de nuestra protagonista. También, como el anterior relato de Ph. de Remy, con el bebé, fruto del matrimonio. Madre e hijo atraviesan el bosque y llegan a Estampes donde la alcaldesa las acoge en su casa; esta vez, entre las protestas de su marido, mercader. Obligada a seguir su camino, se dirige a Orleans para recibir las limosnas del obispo. Allí se apiadará de ellos una pobre mendiga que los acoge hasta ser recibidos en el Hôtel-Dieu, centro episcopal de beneficencia.

Por su parte, el conde, tras conocer la traición de la que ha sido víctima su esposa, inicia su búsqueda como peregrino penitente con el voto de ayunar e ir a pie con la misma vestimenta y el mismo calzado ${ }^{12}$ hasta encontrarla. Se dispone a "mendigar el pan de puerta en puerta por las villas; y para mayor sufrimiento, vistiendo como un mendigo, soportar las peores palabras de desprecio con golpes y maltrato" (vv. 528692). En su recorrido, pide limosna a un villano, de un cura recibirá un ennegrecido mendrugo de pan y dormirá a la intemperie; cuando se acerca a Estampes, es acosado por perros e insultado y menospreciado por sus habitantes (vv. 5422-60). Informado por la misma alcaldesa que había acogido a la esposa y al hijo, se dirige también a Orleans. En una cola de dieciséis mil pobres y mendigos que esperan limosna, recibe palos e insultos de los guardias que ponen orden en la muchedumbre de pordioseros (vv. 5621-99). El limosnero que había atendido a la madre y al niño facilitará al conde el encuentro y el feliz final.

$\mathrm{Si}$, en La Manekine, encontramos grandes viajes por todo el mundo conocido en la época (Hungría, Escocia, Roma, Armenia, la India y el septentrión); por su parte, los personajes de Maillart hacen un recorrido corto; es decir, el posible dentro de sus limitaciones humanas, sin ayuda sobrenatural. Recorren etapas de unas decenas de kilómetros al sudeste de París ${ }^{13}$. El espacio recorrido aumenta veracidad y realismo al ser repetido por nuestra fugitiva y su esposo. Los personajes que encuentran, de condición baja y humilde, toman mayor protagonismo: sicarios y verdugos, un mundo de viudas pobres, alcaldesas, mercaderes y villanos, clérigos, mendigos y limosneros. El comportamiento es el habitual, el cotidianamente observable, lejos de idealización alguna. El espacio recorrido es el que se puede recorrer a pie. El itinerario no es de castillo en castillo sino de burgo en burgo, de ciudad en ciudad ${ }^{14}$. Este tipo de narración lleva consigo la eliminación de lo maravilloso cristiano y de los recursos tradicionales de la narrativa cortés presentes en La Manekine

11 "Mez, s'aucun me fesoit demande / quiex mes ne quans elles mengierent, / je dis que pois reschauféz ierent / du jour devant, et puis des oez. / Male viande iert a leur oez: / du pain noir et de l'iau plate" (vv. 1330-1335).

12 "Des or mes m'estuet esprouver / qu'est povreté et qu'est malaise" (vv. 5254-5).

13 De Angers a Orleans (en la actualidad, $247 \mathrm{~km})$; de Orleans a Lorris $(53 \mathrm{~km})$; de Lorris a Estampes (76 $\mathrm{km})$; y de Estampes a Orleans $(66 \mathrm{~km})$.

14 No olvidemos la importancia que toman las descripciones de ciudades como la de Roma (Mirabilia urbis Romae) en las guías (Rubio 1986: 35). 
(don en blanco, barco sin remo ni vela, torneos, milagros, etc.). Lo maravilloso no cabe en la nueva realidad narrativa.

La reducción a un paisaje preciso y conocido; la importancia de personajes secundarios y populares -los reyes del relato anterior son sustituidos por condes, los senescales y los senadores por burgueses, o alcaldesas o viudas indigentes-; las escenas de la vida cotidiana y popular; un recorrido social por el espacio cerrado y urbano. Es la presentación de una nueva percepción del espacio que designé en otro momento como inmanente ${ }^{15}$. En la literatura llamada realista o gótica de los siglos XIII y XIv, el espacio y su descripción toman protagonismo; elementos caracterizadores de la narrativa de viaje.

\section{Narración viajera y libros de viaje}

Jean Renart abre el camino a un modelo de viaje, el comercial, burgués y realista del siglo XIII; a esta actitud narrativa pertenece la modalidad de los libros de viaje que van a aparecer, una décadas después, en la segunda mitad de este siglo. La nueva concepción del relato prepara y facilita el tipo de narración de los libros de viaje que florece en la segunda mitad de este siglo. Narración literaria y relato de viaje no dejan de estar imbricados.

Paralelamente al desarrollo de la narrativa literaria realista, florece el género de los libros de viaje. En pocos años, aparecen la Historia Mongalorum de fray Juan de Pian de Cárpine y la relación de Benito de Polonia, en 1247; la carta de Sempad, condestable de Armenia, y la Historia Tartorum de Simon de Saint-Quentin, en 1248; en 1255, el Itinerarium de Guillermo de Rubruc; hacia 1270, la relación de David d'Ashby; hacia 1292, la Carta de Juan de Montecorvino; el siglo se cerrará con el Divisament dou monde de Marco Polo (1298).

Lo que entendemos por libro de viaje no deja de tener una doble herencia de la narrativa anterior: si la narración realista o gótica aporta una nueva percepción del espacio, de la bretona o artúrica mantiene el interés por el desenlace en una aventura extraordinaria. El conocimiento de lo extraordinario está también al final del viaje ${ }^{16}$.

El hombre medieval cree vivir en un mundo conocido aunque le sea desconocido "porque-como señala E. Popeanga -todo espacio (real o imaginario) está mencionado o escrito de antemano" (2002: 59).

Surge la necesidad de descubrir lo conocido pero no visto hasta el momento. En el siglo XII, se usa en el sentido de "quitar lo que cubre" y "desvestir" (1230); en el XVI,

15 "El espacio no está lleno de significaciones que lo transcienden sino que nos ofrece, sin más, lo percibido. En este sentido, podemos hablar de una percepción inmanente del espacio", frente al transcendido y neoplatónico del siglo XII (Carmona 2002: 338).

16 Para Bajtin, el cronotopo de la novela caballeresca es "un mundo milagroso en el tiempo de la aventura [subrayado por el autor]" (Bajtin 1989: 306). En cuanto a la narrativa del XIII señalada, podríamos añadir que se trata de un mundo milagroso partiendo del presente cotidiano. Hay una serie de rasgos caracterizadores de la literatura de viaje que no son ajenos a la narrativa artúrica y, en particular, la posterior señalada: 1) en cuanto que "la narración se articula sobre el trazado y recorrido de un itinerario"; 2) adopción de orden cronológico; 3) importancia del orden espacial. Y "un propósito totalizador de describirlo todo, de incorporarlo todo al relato, aunque sólo sea mediante su simple mención” (Pérez Priego 1984: 220-234). 
como "percibir una cosa desde un lugar". "Dar a conocer el primero una cosa ignorada" (Rey 2002: 1012) ${ }^{17}$.

El viajero va reconociendo la geografía bíblica y los seres de su imaginario: unicornio (hipopótamo), etc. Pero el viaje es una experiencia personal, particularmente en cuanto se expresa un testimonio de algo nuevo. Es lo que Eugenia Popeanga ha designado como discurso mixto (2002: 59).

La fusión medieval de espacio y tiempo hace del viaje a Asia un recorrido no sólo espacial sino también temporal; el viaje que nos puede llevar al descubrimiento del Paraíso Terrenal. El viaje va del presente del viajero al principio de la Historia. El viaje medieval es un "proceso continuo de mistificación y desmitificación" (Popeanga 2002: 61). Se desmitifica el recorrido realizado -lo descrito directamente- pero no el destino buscado; como la búsqueda del Paraíso de los conquistadores de América; móvil que les impulsa a recorrer en pocos años un continente, como refleja la toponimia (Amazonas, California, Patagonia, etc.).

Así como el caballero del roman artúrico tiene que luchar con monstruos y seres demoníacos para culminar su aventura en un lugar de difícil acceso, rodeado de agua o aire impenetrable; el Paraíso se concibe de forma similar rodeado de un cinturón de fuego y montañas y de dragones y monstruosas serpientes. Si el público unas décadas anteriores quedaba fascinado con las aventuras extraordinarias de los caballeros, al fin y al cabo "vains et plaisants", el nuevo queda más fascinado porque oye historias extraordinarias vividas realmente.

El relato de viaje de fray Jordán Catalán de Séverac, resume en su título, Mirabilia descripta los dos elementos que sustentan la atracción y fascinación de los libros de viaje y su misma caracterización como género. La descripción de los espacios que recorre responde a un diseño dado. Es un desplazamiento hacia Oriente, haciendo un recorrido contrario al del sol. Recorre un lugar inseparable de su tiempo; es decir, de su historia que, a su vez, se ordena siguiendo el curso solar. La historia va de oriente a occidente, según el tópico de translatio imperii. El viajero siguiendo un curso inverso, hace también un viaje al pasado. En su desplazamiento de Occidente a Oriente, en un caminar inverso al de los astros y al movimiento del tiempo, recorre un espacio que se sitúa entre el que encalló el Arca de Noé y el Paraíso Terrenal.

Viaja para describir (descripta) lo maravilloso (mirabilia) ${ }^{18}$. Es el término que se repite en el relato de Séverac y que justifica lo relatado (mirabilis, mirabile valde, Mirabile magnum, etiam! mirae admirationis!, multa et infinita mirabilia, etc.) La raíz mir (latín: mirare) implica mirada, percepción visual. Valorando lo maravilloso cristiano, lo miraculosus.

Se atiende, pues, a lo que puede ser mirado y admirado; se trata de lo maravilloso real, cuya existencia es garantizada por el testimonio del viajero o por testigos fidedignos: así, el término vidi aparece asociado a mirabile.

17 "Descubrir -escribe Olschki- no significaba solamente encontrar cosas nuevas, sino en primer lugar reconocer en la realidad aquello que la imaginación y una fe tradicional daban por existente" (cit. por Rubio 1987: 26).

18 Entre los siglos VII y x se difunde en Occidente las mirabilia Indiae como la Epistola Premonis regis ad Trajanum Imperatorem, la carta apócrifa de Alejandro a Aristóteles, la correspondencia entre Alejandro y Dindymus y la carta del preste Juan (Rubio Tovar 1987: 22-23). 
En Asia tiene lugar el encuentro entre el espacio real y el espacio imaginario: es el tema fundamental. En un momento histórico determinado, el libro de viajes y el relato de ficción del XIII responden a un mismo "imaginario espacial". Para el cartógrafo medieval "su objetivo es confirmar, no crear un conocimiento" (Zumthor 1994: 312); y "el mapa medieval es un relato" (Zumthor 1994: 324). Hay una fusión, pues, del espacio literario narrativo con el del libro viaje. La tradición literaria, la cultural y filosófica del XIII proporcionan la precisión descriptiva, el interés por el dato tal como es percibido; pero se integra en el imaginario heredado.

Difícilmente se podrá ver aquello que previamente no es conocido o imaginado. Al finalizar el siglo XIII, el imaginario está configurado y va a condicionar la visión del mundo hasta la época moderna. Cristóbal Colón y las relaciones o crónicas de los conquistadores ajustarán la realidad descubierta al espacio medieval imaginado. El descubrimiento del otro, el viaje como revelación de la alteridad, no está referido al sujeto que viaja. Sobre el yo, está el nosotros colectivo. La subjetividad del viajero quedó subordinada al nosotros ${ }^{19}$.

El viajero queda despersonalizado, reducido a testigo, al mero registro de lo percibido. Queda eliminado lo acaecido directamente: su aventura personal. Es lo que echa de menos el lector moderno. Se imponía, pues, el yo colectivo; el nosotros, sobre el individuo.

El imaginario individual integrado en el de la comunidad es entendido como realidad ${ }^{20}$. De aquí, la importancia de la función referencial en los libros de viajes señalada por Eugenia Popeanga ${ }^{21}$. El viajero describe una realidad dada y difícilmente entra su observación y curiosidad en conflicto con ella. La experiencia del viajero aclara la significación de la realidad y no discute su autenticidad ${ }^{22}$. Popeanga lo ha precisado así:

El trasfondo mítico-simbólico que rige en toda creación medieval aflora en algunos libros de viaje, de manera distinta, desconcertante. La aventura de conquista y descubrimiento emprendida como acción y narrada por el autor-viajero permite al público participar de las "maravillas" de un mundo desconocido sin cuestionarse ya si lo contado es verdadero o no (1991b: 26).

Es, por todo ello, por lo que, en la Edad Media, hablamos de libros de viaje antes que de libros de viajeros. Aquellos preceden a estos, pero el relato de ficción narrativa del XIII y principios del xIV anuncia y prepara la llegada de estos últimos.

19 "S'il a bien présence d'une conscience dans les textes, c'est avant tout une conscience colective, suscitée par la découverte d'autres manières de vivre ou de penser" (Guéret-Laferté, 1994: 206).

20 El libro de viajes pretende sustituir una poética de la ficción por otra de la realidad, recurriendo a la descripción.

21 "Se trata de discursos en que la función referencial es fundamental, puesto que lo que se cuenta-comunica representa una referencia continua a un contexto determinado" (1991a: 150).

22 Los viajeros medievales parecen seguir a san Agustín cuando afirma que "lo importante es meditar sobre la significación de un hecho, no discutir su autenticidad" (cit. por Bercovici-Huard, 1976: 223). 


\section{BIBLIOGRAFÍA}

ALIGHIERI, Dante (1949): El convivio. Buenos Aires: Espasa-Calpe.

ALVAR, Carlos (1991): El rey Arturo y su mundo. Madrid: Alianza Editorial.

BAJTIN, Mijail (1989): Teoría y estética de la novela. Madrid: Taurus.

BÉDIER, Joseph (1908-1912): Les légendes épiques,recherches sur la formation des chansons de geste. París: Honoré Champion.

BERCOVICI-HUARD, Carole (1976): "Prolégomènes à l'étude de l'Inde au XIII siècle", Senefiance, Voyage, quête, pèlerinage dans la littérature et la civilisation medievales. Vol. 2: 223-234.

BURCKHARDT, Titus (1999): Chartres y el nacimiento de la catedral. Palma de Mallorca: Medievalia.

CARMONA, Fernando (2001): La mentalidad literaria medieval: Universidad de Murcia: Servicio de Publicaciones.

(2002): "El espacio narativo a la aparición de la literatura de viajes del siglo XIII", Rafael Beltrán (ed.), Maravillas peregrinaciones y utopías: Literatura de viajes en el mundo románico. Valencia: Publicacions de la Universitat de València, 327-342.

(2016): "Locus amoenus / locus horroris: el marco espacio-temporal del combate caballeresco (Erec, Le Bel Inconu, Jaufré, Amadís)", Esther Corral, Elvira Fidalgo y Pilar Lorenzo (eds.), Cantares de amigos. Estudos en homenaxe a Mercedes Brea. Universidade de Santiago de Compostela: Servizo de Publicacións e Intercambio Científico, 207-220.

DUBOST, Francis (1991): "Le château de l'aventure romanesque", Aspects fantastique de la littérature narrative médiévale (XIIème-XIIIème siècles). París: Honoré Champion. Vol. I, 366-389.

DUCE GARCÍA, Jesús (2005): "Fantasías caballerescas: aproximación al motivo de los castillos encantados", Actas del IX Congreso Internacional de la Asociación Hispánica de la Literatura Medieval. Noia (La Coruña). Vol. II, 213-232.

GILSON, Étienne (1976): La filosofía en la Edad Media. Madrid: Editorial Gredos.

GUÉRET-LAFERTÉ, Michèle (1994: Sur les routes de l'Empire Mongol. Ordre rhétorique des rélations de voyage au XIII et XIV siècles». París: Honoré Champion.

LE GOFF, Jacques (1999): La civilización del occidente medieval. Barcelona: Paidós. (1972): La Baja Edad Media. Madrid: Siglo XXI.

LEJEUNE-DEHOUSSE, Rita (1978): "Jean Renart et le roman réaliste au XIII siècle", Le roman jusqu'à la fin du XIII siècle. Grundriss der romanischen Literaturen des Mittelalters. Heidelberg: Carl Winter. Vol. 4/1: 400-453.

LOUISON, Lydie (2004): De Jean Renart à Jean Maillart. Les romans de style gothique. París: Honoré Champion.

MARCHELLO-NIZIA, Christiane (1980): La Manekine. Roman du XIII siècle. París: Stock-Plus Moyen Âge.

PAREDES, Juan (2012): "Le sentiment de la nature dans l'épopée romane. Paysage et description expressive dans la Chanson de Roland", Le Moyen Age. N $^{\circ}$ CXVIII, 1: 75-88. 
PÉREZ PRIEGO, Miguel Ángel (1984): "Estudio literario de los libros de viajes medievales", Epos. No. I: 217-239.

POPEANGA, Eugenia (1991a): "El discurso medieval en los libros de viajes", Revista de Filología Románica. № 8: 149-162.

(1991b): "Lectura e investigación de los libros de viaje medievales", Revista de Filología Románica. Los libros de viajes en el mundo románico, Anejo I: 9-26. (2002): "Viajeros en busca del Paraíso Terrenal”, Rafael Beltrán (ed.), Maravillas peregrinaciones y utopías: Literatura de viajes en el mundo románico. Valencia: Publicacions de la Universitat de València, 59-75.

REY, Alain (2002): Dictionnaire historique de la langue française. París: Robert.

ROQUES, Mario, ed. (1964): Jehan Maillart. Le roman du comte d'Anjou: París: Honoré Champion.

RUBIO TOVAR, Joaquín (1987): Libros españoles de viajes medievales. Madrid: Taurus. SWEETSER, Franklin, ed. (1974): Jean Renart. L'Escoufle. Roman d'aventure. ParisGenève: Droz.

ZUMTHOR, Paul (1994): La medida del mundo. Representación del espacio en la Edad Media. Madrid: Cátedra.

\section{PERFIL ACADÉMICO Y PROFESIONAL}

Fernando Carmona Fernández es catedrático emérito de la Universidad de Murcia. Ha publicado más de un centenar de artículos y trabajos; y una veintena de libros (monografías, traducciones y ediciones de congresos y coloquios). Particularmente, sus trabajos se han referido a textos medievales y algunos de ellos a libros de viaje.

Fecha de recepción: 04-03-2021

Fecha de aceptación: 15-04-2021 